\title{
Recommendations for increasing research on co-occurring serious mental illness and gambling problems
}

\section{Commentary on: Disordered gambling and psychosis: Prevalence and clinical correlates (Cassetta et al., 2018)}

\author{
REBECCA E. PULLMAN ${ }^{1}$, MARC N. POTENZA ${ }^{2,3,4}$ and SHANE W. KRAUS ${ }^{5,6 *}$ \\ ${ }^{1}$ Mental Health Service Line, Manchester VA Medical Center, Manchester, NH, USA \\ ${ }^{2}$ Departments of Psychiatry and Neuroscience, Child Study Center, Yale University School of Medicine, New Haven, CT, USA \\ ${ }^{3}$ Connecticut Mental Health Center, New Haven, CT, USA \\ ${ }^{4}$ Connecticut Council on Problem Gambling, Wethersfield, CT, USA \\ ${ }^{5}$ VISN 1 New England MIRECC, Edith Nourse Rogers Memorial VA Hospital, Bedford, MA, USA \\ ${ }^{6}$ Division of Addiction Psychiatry, Department of Psychiatry, University of Massachusetts Medical Psychology, Worcester, MA, USA
}

(Received: June 4, 2018; revised manuscript received: September 10, 2018; accepted: September 10, 2018)

\begin{abstract}
Psychiatric disorders frequently co-occur with gambling disorder. Although community and clinical samples show frequent co-occurrence between gambling and psychotic disorders, relatively little research has been conducted on this population. Here, we comment on a recent study conducted in Brazil on the clinical correlates of psychotic disorders in treatment-seeking individuals with gambling disorder, relate the findings to those from the northeastern region of the United States, and discuss implications with respect to promoting responsible gambling in the setting of the expansion of legalized gambling.
\end{abstract}

Keywords: problem gambling, gambling disorder, serious mental illness, treatment, prevention

\section{INTRODUCTION}

A recent study from Brazil of treatment-seeking individuals with gambling problems reported on the significance of the co-occurrence of gambling disorder with psychotic disorders, corroborating and extending findings from studies in the United States of gambling problems in individuals with psychotic disorders and from studies in the United States of community samples. Recently, researchers (Cassetta, Kim, Hodgins, McGrath, \& Tomfohr-Madsen, 2018) studied the presence of co-occurring psychotic disorders and found it was associated with increased likelihoods of specific psychiatric concerns, particularly agoraphobia and suicidality. As such, considering how best to prevent and treat problem gambling in individuals with psychotic disorders warrants additional investigation, particularly as among other vulnerable groups (e.g., individuals with co-occurring alcohol and mental health disorders), the presence of gambling problems has been associated with poorer mental health outcomes (Grant, Potenza, Kraus, \& Petrakis, 2017). Such a focus appears particularly relevant in the setting of the expansion of legalized gambling in many areas around the world at a time when many jurisdictions have limited support for research, prevention, and treatment efforts related to problem gambling (Nature, 2018; Weinstock, 2018). Specific to this commentary, we discuss considerations in the context of current changes in the state of Massachusetts and federally in the United States.

The introduction of new casinos and expansion of other forms of gambling in Massachusetts have increased the need to address problem gambling in this region of the United States. The Expanded Gaming Act, created in 2016 to allow development of three casinos and a slot-machine venue, is anticipated to provide 15-20 million dollars for prevention and treatment of problem gambling when fully funded. Throughout the United States, problem-gambling-treatment programs are largely underfunded, and the Expanded Gaming Act will comprise approximately one third of the total amount of money spent on problem gambling in the United States (Driscoll, 2016). Recently, the United States Supreme Court has expanded the legality of sports gambling, an activity that is favorite among individuals with psychotic disorders who gamble frequently (Yakovenko, Fortgang, Prentice, Hoff, \& Potenza, 2018). In this changing gambling environment, increased research assessing the impact of problem gambling on vulnerable individuals, such as those

* Corresponding author: Shane W. Kraus, PhD; VISN 1 New England MIRECC, Edith Nourse Rogers Memorial Veterans Hospital, 200 Spring Road, Building 5, Room 135B, Bedford 01730, MA, USA; Phone: +1 7816872000 ext. 5001; Fax: +1 781687 3228; E-mail: shane.kraus@va.gov

This is an open-access article distributed under the terms of the Creative Commons Attribution-NonCommercial 4.0 International License, which permits unrestricted use, distribution, and reproduction in any medium for non-commercial purposes, provided the original author and source are credited, a link to the CC License is provided, and changes - if any - are indicated. 
diagnosed with serious mental illness (SMI) like schizophrenia and schizoaffective disorder, is needed (Fortgang, Hoff, \& Potenza, 2018). Additional research is needed on how best to prevent and treat gambling problems in vulnerable populations. Such efforts are needed to promote responsible gambling in the setting of gambling expansion, particularly in Massachusetts.

Despite evidence indicating that SMI frequently co-occurs with problem gambling (Cassetta et al., 2018; Desai \& Potenza, 2009) and that the co-occurrence may be associated with significant negative impacts (Yakovenko, Clark, Hodgins, \& Goghari, 2016), there are limited available data, and increased research efforts could help fill existing knowledge gaps and improve current screening and treatment of gambling problems in individuals with SMI (Yakovenko et al., 2018). As shown in Table 1, we have outlined knowledge gaps related to problem gambling and SMI.

\section{PREVALENCE}

Individuals with psychosis are estimated to be four times more likely than those in the general population to have problem gambling (Haydock, Cowlishaw, Harvey, \& Castle, 2015). Individuals with SMI seemingly represent an at-risk population for problem gambling, and more research on the prevalence of gambling within this population can serve to drive further implementation of prevention and treatment efforts.

Negative and socially related symptoms and presentation in many SMI diagnoses suggest there could be differences in what type of gambling behaviors individuals with SMI may prefer as compared to a general population. However, this information is limited. Of 151 individuals with gambling disorders surveyed, $60.9 \%$ of those who had engaged in gambling used electronic machines, $25.8 \%$ horse racing, $25.2 \%$ lottery, $19.2 \%$ scratch tickets, and $18.5 \%$ casino table gambling (Haydock et al., 2015).

\section{SCREENING}

As efforts to screen at-risk populations for problem gambling increase, further attention to screen individuals with SMI is warranted. Case reports exist describing problem gambling in individuals treated with aripiprazole, a partial dopamine agonist used in the treatment of individuals with SMI. These reports warrant further study in order to better understand how best to treat individuals with co-occurring SMI and problem gambling (Echeburua, Gomez, \& Freixa, 2017).

\section{TREATMENT}

Individuals dually diagnosed with co-occurring substanceuse disorders and psychotic disorders are considered a vulnerable clinical population in regard to problem gambling (Haydock et al., 2015). Among individuals with schizophrenia or schizoaffective disorder, comorbid problem gambling, alcohol-use disorders, and other substance-use disorders are conditions linked to one another and of concern for treatment (Desai \& Potenza, 2009). Individuals with schizophrenia or schizoaffective disorder, who also engaged in either recreational or problem gambling, evidenced more frequent mental health services utilization (Mangrum, Spence, \& Lopez, 2006), suggesting that greater implementation of treatment for these issues could address high-frequency users. Specifically, Mangrum et al. (2006) suggested that integrated and long-term treatment for co-occurring SMI and substance-use disorders results in lower rates of arrest, acute hospitalization, and substance use and increased engagement in treatment.

\section{POTENTIAL RISK FACTORS}

The previously mentioned research highlights relationships between psychosis and problem gambling (Cassetta et al., 2018; Haydock et al., 2015). Without further research into these relationships, it is difficult to ascertain risk factors among individuals with SMI. Further knowledge of risk factors may inform targeted prevention and treatment efforts. Research on problem-gambling severity and type of diagnosis or symptomatology could help direct effective treatment approaches in Massachusetts, across the United States and elsewhere in the world.

Table 1. Knowledge gaps and future directions related to problem gambling and SMI

\begin{tabular}{|c|c|}
\hline Current gaps & Future directions \\
\hline $\begin{array}{l}\text { Prevalence } \\
\text { data }\end{array}$ & $\begin{array}{l}\text { Implement studies investigating prevalence of gambling problems among individuals with SMI using samples that are } \\
\text { demographically and geographically diverse, and which include measures of symptom severity and types of gambling } \\
\text { that are common in this population }\end{array}$ \\
\hline Screening & $\begin{array}{l}\text { Screening instruments for assessing gambling problems within this population should be developed, validated, and } \\
\text { utilized, given the research suggesting increased risk and need for treatment. Research investigating the effectiveness of } \\
\text { current screening measures within populations with SMI is needed }\end{array}$ \\
\hline Treatment & $\begin{array}{l}\text { Many programs for SMI incorporate life skills training, social skills training, and other types of treatment to address } \\
\text { symptoms are often experienced by individuals with SMI. There is need for standardized treatment approaches specific to } \\
\text { individuals with SMI }\end{array}$ \\
\hline Risk factors & Further research investigating potential risk factors linked to gambling problems among individuals with SMI is needed \\
\hline Prevention & $\begin{array}{l}\text { Provide education to health care providers about the elevated frequency of gambling problems among individuals with } \\
\text { SMI and encourage implementation of prevention efforts such as providing education to those individuals newly } \\
\text { diagnosed with SMI about gambling disorder }\end{array}$ \\
\hline
\end{tabular}

Note. SMI: serious mental illness. 


\section{PREVENTION}

Massachusetts utilized the Expanded Gaming Act to increase funding for the prevention and treatment of problem gambling. These types of programs are currently implemented in the United States on a state-by-state basis (Driscoll, 2016). Increased research on gambling, including in specific populations such as those with SMI, should provide evidence for funding prevention programs.

Finally, the need for increased efforts to support prevention and treatment efforts for problem gambling is evident. Available data indicate that individuals with SMI appear to have increased need for targeted services for problem gambling. Increasing the amount of research on SMI and problem gambling may benefit individuals by informing appropriate, targeted prevention, and treatment efforts. Working together with involved stakeholders to promote responsible gambling in the setting of the expansion of legalized gambling has the greatest likelihood of preventing harm, particularly among vulnerable populations, and promoting public health. Collaborative efforts involving groups involved in gambling research, industry, and advocacy are currently underway (Ponseti, 2018), and these efforts have significant potential to advance our understanding of, and promote the implementation of, empirically supported interventions to prevent harms related to gambling.

Funding sources: The authors were supported during writing phases by the Department of Veterans Affairs, VISN 1 New England MIRECC, the Massachusetts Gaming Commission (BD-17-1068-1068C-1068L-13699), the Connecticut Council on Problem Gambling, and the National Center for Responsible Gaming. REP and SWK are full-time employees of the Department of Veterans Affairs. The content of this manuscript does not necessarily reflect the views of the funding agencies and reflects the views of the authors.

Authors' contribution: REP conceptualized and wrote the initial draft. MNP and SWK contributed to the revision of the draft and approved the final version of the manuscript.

Conflict of interest: None of the authors have any conflicts of interest.

\section{REFERENCES}

Cassetta, B. D., Kim, H. S., Hodgins, D. C., McGrath, D. S., \& Tomfohr-Madsen, L. M. (2018). Disordered gambling and psychosis: Prevalence and clinical correlates. Schizophrenia Research, 192, 463-464. doi:10.1016/j.schres.2017.04.006
Desai, R. P., \& Potenza, M. N. (2009). A cross-sectional study of problem and pathological gambling in patients with schizophrenia/schizoaffective disorder. Journal of Clinical Psychiatry, 70(9), 1250-1257. doi:10.4088/JCP. m04359

Driscoll, E. (2016). The Massachusetts Gaming Commission observes March 2016 as National Problem Gambling Awareness Month. Massachusetts Gaming Commission. Retrieved from https://massgaming.com/blog-post/the-massachusetts-gamingcommission-observes-march-2016-as-national-problemgambling-awareness-month

Echeburua, E., Gomez, M., \& Freixa, M. (2017). Prediction of relapse after cognitive-behavioral treatment of gambling disorder in individuals with chronic schizophrenia: A survival analysis. Behavior Therapy, 48(1), 69-75. doi:10.1016/j. beth.2016.09.008

Fortgang, R. G., Hoff, R. A., \&Potenza, M. N. (2018). Problem and pathological gambling in schizophrenia: Exploring links with substance use and impulsivity. Journal of Gambling Studies, 34(3), 1-16. doi:10.1007/s10899-018-9757-z

Grant, J. E., Potenza, M. N., Kraus, S. W., \& Petrakis, I. L. (2017). Naltrexone and disulfiram treatment response in veterans with alcohol dependence and co-occurring problem-gambling features. Journal Clinical Psychiatry, 78(9), e1299-e1306. doi:10.4088/JCP.16m11220

Haydock, M., Cowlishaw, S., Harvey, C., \& Castle, D. (2015). Prevalence and correlates of problem gambling in people with psychotic disorders. Comprehensive Psychiatry, 58, 122-129. doi:10.1016/j.comppsych.2015.01.003

Mangrum, L. F., Spence, R. T., \& Lopez, M. (2006). Integrated versus parallel treatment of co-occurring psychiatric and substance use disorders. Journal of Substance Abuse Treatment, 30, 79-84. doi:10.1016/j.jsat.2005.10.004

Nature. (2018). Science has a gambling problem. Nature, 553(7689), 379. doi:10.1038/d41586-018-01051-z

Ponseti, C. (2018, April 18). Industry, academics and advocates unite to launch responsible gaming collaborative. American Gaming Association. Retrieved from https://www. americangaming.org/newsroom/press-releasess/industryacademics-and-advocates-unite-launch-responsible-gaming

Weinstock, J. (2018). Call to action for gambling disorder in the United States. Addiction, 113(6), 1156-1158. doi:10.1111/add. 14225

Yakovenko, I., Clark, C. M., Hodgins, D. C., \& Goghari, V. M. (2016). A qualitative analysis of the effects of a comorbid disordered gambling diagnosis with schizophrenia. Schizophrenia Research, 171(1), 50-55. doi:10.1016/j.schres.2015. 12.008

Yakovenko, I., Fortgang, R., Prentice, J., Hoff, R., \& Potenza, M. (2018). Correlates of frequent gambling and gambling-related chasing behaviors in individuals with schizophrenia-spectrum disorders. Journal of Behavioral Addictions, 7(2), 375-383. doi:10.1556/2006.7.2018.31 